\title{
openheart Gender differences in health-related quality of life in patients undergoing coronary angiography
}

Crystel M Gijsberts, ${ }^{1,2}$ Pierfrancesco Agostoni, ${ }^{3}$ Imo E Hoefer, ${ }^{1}$ Folkert W Asselbergs, ${ }^{3,4,5}$ Gerard Pasterkamp, ${ }^{1}$ Hendrik Nathoe, ${ }^{3}$ Yolande E Appelman, ${ }^{6}$ Dominique P V de Kleijn, ${ }^{1,2,7,8}$ Hester M den Ruijter $^{1}$

To cite: Gijsberts CM, Agostoni P, Hoefer IE, et al. Gender differences in healthrelated quality of life in patients undergoing coronary angiography. Open Heart 2015;2:e00231.

doi:10.1136/openhrt-2014000231

- Additional material is available. To view please visit the journal (http://dx.doi.org/ 10.1136/openhrt-2014000231)

Received 10 December 2014 Revised 8 June 2015 Accepted 9 June 2015

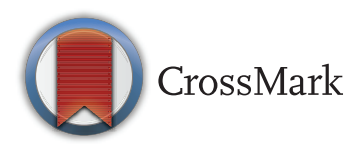

For numbered affiliations see end of article.

\section{Correspondence to} Crystel M Gijsberts; c.m. gijsberts@umcutrecht.nl

\section{ABSTRACT}

Background: Health-related quality of life (HRQOL) reflects the general well-being of individuals. In patients with coronary artery disease (CAD), HRQOL is compromised. Female patients with CAD have been reported to have lower HRQOL. In this study, we investigate gender differences in HRQOL and in associations of patient characteristics with HRQOL in patients with coronary angiography (CAG).

Methods: We cross-sectionally analysed patients from the Utrecht Coronary Biobank undergoing CAG. All patients filled in an HRQOL questionnaire (RAND-36 and EuroQoL) on inclusion. RAND-36 and EuroQoL HRQOL measures were compared between the genders across indications for CAG, CAD severity and treatment of CAD. RAND-36 HRQOL measures were compared with the general Dutch population. Additionally, we assessed interactions of gender with patient characteristics in their association with HRQOL (EuroQoL).

Results: We included 1421 patients (1020 men and 401 women) with a mean age of 65 in our analysis. Women reported lower HRQOL measures than men (mean EuroQoL self-rated health grade $6.84 \pm 1.49$ in men, $6.46 \pm 1.40$ in women, $p<0.001$ ). The reduction in RAND-36 HRQOL as compared with the general Dutch population was larger in women than in men. From regression analysis, we found that diabetes, a history of cardiovascular disease and symptoms of shortness of breath determined HRQOL (EuroQoL) more strongly in men than in women.

Conclusions: Women reported lower HRQOL than men throughout all indications for CAG and regardless of CAD severity or treatment. As compared with the general population, the reduction in HRQOL was more extreme in women than in men. Evident gender differences were found in determinants of HRQOL in patients undergoing $C A G$, which deserve attention in future research.

Trial registration: NCT02304744 (clinicaltrials.gov).

\section{INTRODUCTION}

Since survival of patients with coronary artery disease (CAD) keeps improving, their health-related quality of life (HRQOL) is of

\section{KEY QUESTIONS}

What is already known about this subject?

- It is known that cardiovascular risk factors and cardiovascular disease are related to diminished quality of life. Men dominate the cardiovascular research population, while prevalence and mortality from coronary artery disease in women are equally high. Gender-specific analyses in cardiovascular disease are on the rise, but many aspects remain to be elucidated.

What does this study add?

- In this study, we analyse the health-related quality of life separately in men and women. We do this in a cohort comprising all patients with coronary angiography, capturing all indications and severities. Furthermore, we analyse the association of cardiovascular risk factors with quality of life separately in men and women.

How might this impact on clinical practice?

- We find that all women in our cohort, as well as women who have no stenoses in their epicardial vessels, report lower quality of life than men. This might indicate that these women suffer from chest pain (or equivalent) symptoms for other reasons than epicardial coronary artery disease. More efforts should be undertaken to understand the aetiology of their symptoms. In a clinical setting, one may consider investigations and treatment of microvascular coronary artery disease in these women, as their symptoms have as much impact on quality of life as in women with significant epicardial disease.

high relevance. A poor HRQOL is related to higher healthcare expenditure, ${ }^{1}$ and therefore it has become an increasingly important point of interest to physicians. More and more frequently, HRQOL is used as an outcome measure in clinical research to assess, for example, the effect of treatments. ${ }^{2}$

HRQOL has been reported to be associated with several cardiovascular risk factors. For example, obesity, ${ }^{3}{ }^{4}$ diabetes $^{5}$ and 
smoking $^{6}$ all have been linked to a diminished HRQOL, but up until now it is unclear whether this holds true for both men and women, as the majority of the cardiovascular disease (CVD) research has focused on men. However, evidence has emerged in primary care and primary prevention settings which shows differences in the association of risk factors with HRQOL between men and women (eg, for obesity, ${ }^{7}$ diabetes $^{8}$ and smoking $^{9}$ ).

While CVD has long been considered a men's disease, global mortality from CVD is equal between men and women. ${ }^{10}$ In the USA, the GVD mortality rate for women even exceeds that for men. ${ }^{11}$ Furthermore, in population studies, angina pectoris is more prevalent among women $(6.7 \%)$ than men $(5.7 \%),{ }^{12}$ and women suffer from longer delays in the case of suspected acute coronary syndrome. ${ }^{13} 14$ Women who eventually undergo percutaneous coronary intervention $(\mathrm{PCI})^{15} 16$ or coronary artery bypass grafting $(\mathrm{CABG})^{17}$ report lower HRQOL. Up until now, it is unknown whether all women who undergo coronary angiography (CAG) with or without PCI express the same low HRQOL scores, or if low HRQOL scores are found in particular subgroups of the female patients with CAG. Increased acknowledgement and understanding of gender differences in patient characteristics that determine low HRQOL may lead to better treatment and more personalised care.

Therefore, first, we investigated gender differences in reported HRQOL in a CAG population. Second, we examined gender differences in HRQOL across the indications for CAG, the angiographic severity of CAD and across the treatment strategies of CAD. Additionally, for men and women separately, we evaluated differences in HRQOL among the indications for CAG, the angiographic severity of $\mathrm{CAD}$ and across the treatment for CAD. Third, we evaluated the difference in HRQOL between men and women undergoing CAG as compared with the general Dutch population, in order to evaluate gender discrepancies in the difference with the general population. Finally, we hypothesised that patient characteristics and angina symptoms were associated with lower HRQOL in dissimilar ways between men and women undergoing CAG.

\section{METHODS}

\section{Patient selection}

We performed a cross-sectional study in the Utrecht Coronary Biobank (UCORBIO) cohort, registered under clinicaltrials.gov ID: NCT02304744. This ongoing biobank started enrolment in October 2011. All patients who were enrolled between October 2011 and March 2014 were included in the current analyses. Also, all patients entering the catheterisation laboratories of the University Medical Centre in Utrecht (the Netherlands) were asked to participate in this biobank. Here, patients with all indications for CAG were included. The study has been approved by the medical ethical committee of the University Medical Centre Utrecht (registration code 11-183) and all patients provided written informed consent. The only exclusion criterion was age $<18$ years. According to the study protocol, all patients who provided written informed consent were provided with an HRQOL questionnaire. Patients who returned the HRQOL questionnaire (described in more detail below) were considered for this study.

The process of patient recruitment and selection is depicted in figure 1. Between October 2011 and March 2014, 3405 patients underwent CAG, of whom 2268 were asked to participate in UCORBIO. A total of 1993 patients provided informed consent, of whom 1421 returned the HRQOL questionnaire. Thus, the response rate was $71.6 \%$. The response rate did not differ between men and women.

\section{Data collection}

HRQOL questionnaire

Our HRQOL questionnaire contained the RAND-36 questionnaire V.1, consisting of nine domains of HRQOL: physical functioning, mental functioning, social functioning, physical role limitations, emotional role limitations, pain, vitality, general health and health change. The internal consistency of this questionnaire has previously been established to be high with Cronbach's $\alpha$ ranging from 0.71 to 0.92 across the domains. ${ }^{18}$ We extended the RAND-36 questionnaire with the self-rated health grading question derived from the EuroQoL ${ }^{19}$

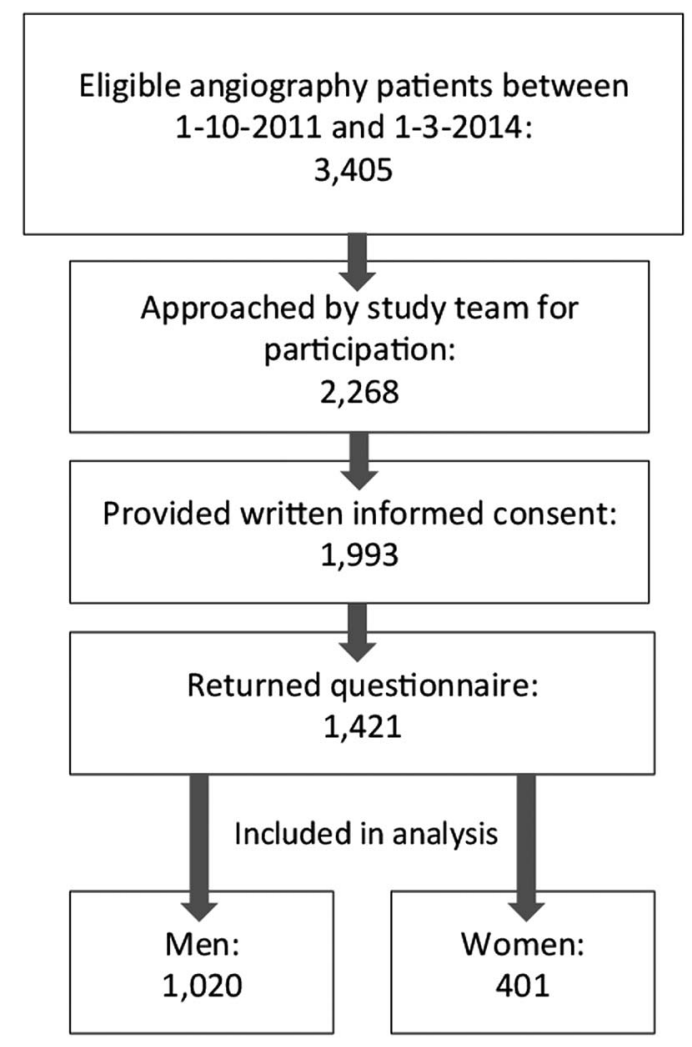

Figure 1 Flow chart of patient recruitment and selection process. 
questionnaire ('Please indicate how good or bad your health is on a scale from 0 (worst) to 10 (best)').

The questionnaire was handed to the patients directly after CAG. Patients were instructed to fill in the questionnaire according to their situation prior to CAG. Patients were allowed to take home and send back the questionnaire. The median time between CAG and return of the study number coded questionnaire to the research office (by mail) was 112 days.

\section{Medical records}

At baseline, demographical data, history of CVD (previous acute coronary syndrome, previous PCI, previous CABG, cerebrovascular accident or peripheral arterial disease), medication use, cardiovascular risk factors (diabetes, smoking, body mass index (BMI), hypertension, hypercholesterolaemia and family history of CVD), and clinical data concerning the indication for CAG, the angiographic severity of CAD and details from the procedure were collected from the medical records.

The indication for catheterisation was grouped into stable CAD (stable angina, dyspnoea on exertion or silent myocardial ischaemia), unstable angina, myocardial infarction (non-ST elevation myocardial infarction (NSTEMI) or ST elevation myocardial infarction (STEMI) ) and other indications (mostly screening for valve surgery).

The angiographic severity of CAD was determined by the number of epicardial vessels with an angiographic stenosis of $>50 \%$ based on visual assessment or with a significant intracoronary fractional flow reserve (FFR) measurement $(<0.75)$. The angiographic severity of CAD was grouped into four groups: normal coronaries (no or minor CAD with $<50 \%$ stenosis), single-vessel disease, double-vessel disease and triple-vessel disease.

\section{Anginal symptoms questionnaire}

The characteristics of anginal symptoms were obtained through a patient questionnaire, based on the Rose and Blackburn ${ }^{20}$ cardiovascular questionnaire. This questionnaire was combined with the HRQOL questionnaire and thus sent and returned at the same time as the HRQOL questionnaire. Six questions were asked: type of symptoms (chest pain, dyspnoea, no symptoms or other), progression of symptoms (yes or no), circumstances of symptoms (exercise, cold, emotion, in absence of exercise, cold or emotion), start of symptoms (more than 10 years ago, 5-10 years ago, 1-5 years ago or less than 1 year ago), last occurrence of symptoms (more than 1 year ago, 1 year to 1 month ago, 1 month to 1 week ago or last week) and limitations due to symptoms (none, mild, severe or no activity possible).

\section{General Dutch population}

Data on HRQOL scores in the general Dutch population were derived from the Dutch manual on the RAND-36 questionnaire, presenting the scores of 1036 randomly selected adult test subjects aged between 18 and 89 (mean 44.1). For the general population, ageand gender-specific HRQOL means were reported by van der Zee and Sanderman. ${ }^{21}$ Therefore, we could only perform a gender-matched comparison to a general population sample that was younger than our study population. To the best of our knowledge, no EuroQoL means are available for the general Dutch population.

\section{Computation of RAND-36 HRQOL scores}

For the interpretation of the RAND-36 data, the SPSS syntax provided by the University of Groningen ${ }^{22}$ was used. This syntax calculates one score for each domain, composed of several domain items. The physical functioning domain consisted of 10 items, each to be scored from 1 to 3 . The social functioning domain consisted of two domains to be scored from 1 to 5 . The physical role functioning domain consisted of four items to be scored 1 or 2 , while the emotional role functioning domain consisted of three items to be scored 1 or 2 . The mental functioning domain comprised five questions to be scored from 1 to 6 , while the vitality domain comprised four questions to be graded from 1 to 6 . The pain domain consisted of two questions, the first to be scored from 1 to 6 , and the second to be scored from 1 to 5 . The general health domain comprised five questions, to be scored from 1 to 5 , and health change was a single item to be scored from 1 to 5 .

The total domain score was calculated when at least half of the items were answered. First, a mean score per domain was calculated. Subsequently, the mean score was transformed to a percentage of the highest possible score on each domain. Those percentages were used in the current analysis.

\section{Data analysis}

Data analysis was performed using IBM SPSS Statistics, V.20 and R software for statistical computing, V.3.1.2. ${ }^{23}$ Continuous data were presented as means $\pm \mathrm{SD}$ when normally distributed. Non-normally distributed continuous data were presented as median with IQR. Categorical data were presented as percentages per category and were compared using a $\chi^{2}$ test. Means were compared using a Student $\mathrm{t}$ test for normally distributed data. Significance level was set at $\alpha<0.05$. Complete case analyses were performed. Questionnaire consistency was tested with Cronbach's $\alpha$ for the RAND-36 questionnaire.

Our primary analysis consisted of a univariable comparison of HRQOL between men and women. These gender differences in the domains of RAND-36 HRQOL were compared using a Mann-Whitney U test, as these data were non-normally distributed. Also, in order to get a better idea of the gender differences in HRQOL (RAND-36 and EuroQoL self-rated health grade), we stratified the analyses by CAD severity, indication for $\mathrm{CAG}$ and treatment of CAD and looked into differences in HRQOL scores across indication, severity and treatment of CAD using Kruskal-Wallis testing with 
Bonferroni post hoc pairwise comparisons. Additionally, we compared HRQOL scores of our cohort to the general Dutch population. Only means and SDs of the general population scores were available, and thus these were used (inappropriately, as they are non-normally distributed) to perform a Student $\mathrm{t}$ test between the general population and our patient sample.

Our secondary analysis consisted of univariable and multivariable regression analysis of patient characteristics (cardiovascular risk factors and symptom characteristics) associated with EuroQoL HRQOL, with interaction terms for gender. We chose the EuroQoL self-rated health grade as an outcome measure for this analysis, as we assumed that it would provide the best overall representation of HRQOL. Gender-specific regression coefficients from univariable and multivariable analyses as well as $p$ values for interactions with gender were generated.

\section{RESULTS}

The response rates for the HRQOL questionnaire were similar for men $(71.2 \%)$ and women $(72.5 \%)$. In total, 1020 men (comprising $71.8 \%$ of the study population) and 401 women were available for analysis. Patient characteristics of the responders are shown in table 1 , stratified by gender. The mean age was 64.2 years for men and 66.8 years for women $(\mathrm{p}<0.001)$. Men had a higher BMI than women: 27.1 vs $26.7, \mathrm{p}=0.009$. Women more often had a history of hypertension than men (62.1\% vs $56.0 \%, \mathrm{p}=0.002)$. Hypercholesterolaemia, a history of CVD and smoking were significantly more prevalent among men. There were no gender differences among the indications for CAG between men and women. CAG in women more often revealed normal coronaries than in men, and women were subsequently more often treated conservatively than men.

\section{Table 1 Patient characteristics and reported HRQOL scores stratified by gender}

\begin{tabular}{|c|c|c|c|c|c|c|}
\hline & Men & Valid N & Women & Valid N & Test value & p Value \\
\hline \multicolumn{7}{|l|}{ Demographics } \\
\hline $\mathrm{N}$ (responders, \% of total cohort) & 71.2 & 1020 & 72.5 & 401 & & 0.6 \\
\hline Age (years, mean $\pm S D$ ) & $64.2 \pm 10.7$ & 1020 & $66.8 \pm 11.4$ & 401 & 4.00 & $<0.001$ \\
\hline $\mathrm{BMI}\left(\mathrm{kg} / \mathrm{m}^{2}\right.$, mean $\left.\pm \mathrm{SD}\right)$ & $27.1 \pm 4.2$ & 1018 & $26.7 \pm 5.0$ & 398 & 4.32 & 0.009 \\
\hline Diabetes (\%) & 21.7 & 1008 & 21.0 & 391 & 0.07 & 0.9 \\
\hline Hypertension (\%) & 56.0 & 996 & 62.1 & 390 & 4.31 & 0.002 \\
\hline Hypercholesterolaemia (\%) & 50.8 & 985 & 44.6 & 383 & 3.99 & 0.05 \\
\hline Smoking (ever \%) & 54.8 & 899 & 42.2 & 344 & 16.03 & $<0.001$ \\
\hline History of CVD (\%) & 56.2 & 1020 & 44.1 & 401 & 16.73 & $<0.001$ \\
\hline Indication for CAG & & 1020 & & 401 & 1.90 & 0.5 \\
\hline Stable CAD (\%) & 64.9 & & 67.6 & & & \\
\hline UA (\%) & 8.2 & & 9.0 & & & \\
\hline Myocardial infarction (\%) & 23.5 & & 20.4 & & & \\
\hline Other (\%) & 3.4 & & 3.0 & & & \\
\hline CAD severity & & 1004 & & 391 & 38.09 & $<0.001$ \\
\hline Normal coronaries (\%) & 20.6 & & 36.3 & & & \\
\hline 1-vessel disease (\%) & 35.1 & & 30.7 & & & \\
\hline 2-vessel disease (\%) & 28.7 & & 21.5 & & & \\
\hline 3-vessel disease (\%) & 15.6 & & 11.5 & & & \\
\hline Treatment of CAD & & 1014 & & 397 & 19.91 & $<0.001$ \\
\hline Conservative (\%) & 31.9 & & 44.6 & & & \\
\hline $\mathrm{PCl}(\%)$ & 61.8 & & 50.1 & & & \\
\hline CABG (\%) & 6.3 & & 5.3 & & & \\
\hline \multicolumn{7}{|l|}{ HRQOL } \\
\hline EuroQoL self-rated health grade (mean, SD) & $6.84(1.49)$ & 997 & $6.46(1.40)$ & 386 & 4.32 & $<0.001$ \\
\hline Physical functioning (median (\%), IQR) & $80(55-95)$ & 993 & $60(35-80)$ & 398 & 9.39 & $<0.001$ \\
\hline Social functioning (median (\%), IQR) & $75(62.5-100)$ & 1004 & $62.5(37.5-87.5)$ & 397 & 6.76 & $<0.001$ \\
\hline Physical role limitations (median (\%), IQR) & $75(0-100)$ & 978 & $25(0-100)$ & 375 & 6.24 & $<0.001$ \\
\hline Emotional role limitations (median (\%), IQR) & $100(66.7-100)$ & 969 & $100(33.3-100)$ & 365 & 3.48 & $<0.001$ \\
\hline Mental functioning (median (\%), IQR) & $80(68-88)$ & 998 & $72(60-84)$ & 388 & 6.29 & $<0.001$ \\
\hline Vitality (median (\%), IQR) & $60(45-75)$ & 998 & $50(35-65)$ & 390 & 7.20 & $<0.001$ \\
\hline Pain (median (\%), IQR) & $79.6(57.1-100)$ & 1001 & $67.3(44.9-100)$ & 389 & 4.56 & $<0.001$ \\
\hline General health (median (\%), IQR) & $60(40-70)$ & 997 & $50(25-75)$ & 389 & 5.37 & $<0.001$ \\
\hline Health change (median (\%), IQR) & $50(25-50)$ & 1003 & $50(25-75)$ & 393 & 0.68 & 0.5 \\
\hline Response delay in days (median, IQR) & $105(21-324)$ & 1020 & $125(23-370)$ & 401 & 1.69 & 0.19 \\
\hline
\end{tabular}




\section{Self-reported anginal symptoms}

Women more often reported shortness of breath than men; also, they experienced progressive symptoms more often than men (table 2). Men significantly more often reported no symptoms $(17.5 \%$ vs $9.7 \%)$ as compared with women.

The triggers of symptoms differed between men and women. In women, emotion was more often a trigger than in men. Also, women more often reported no triggers for their symptoms when compared with men. The time since the start of the symptoms did not differ between men and women, although slightly more men had a very long history of symptoms ( $>10$ years). Women were more likely to have symptoms since $1-10$ years.

The time since last symptoms (prior to CAG) was shortest in women; more women than men experienced their symptoms in the week prior to CAG $(32.1 \%$ vs. $24.9 \%$ ), indicating that women had symptoms more recent to CAG than men. Significantly more men than women experienced no limitations due to their symptoms. More women than men experienced mild limitations. Severe limitations or a state in which no activity is possible was equally common in men and women.

\section{RAND-36 questionnaire consistency}

In our study, Cronbach's $\alpha$ for internal consistency of the RAND-36 questionnaire was 0.87. Cronbach's $\alpha$ for consistency among the items of each domain was 0.93 for the physical functioning domain, 0.83 for social functioning, 0.92 for physical role limitations, 0.90 for emotional role limitations, 0.85 for mental functioning, 0.84 for vitality, 0.90 for pain and 0.81 for general health. The health change domain consisted of a single item; therefore, no consistency could be assessed. Overall, these values correspond to high consistency of the questionnaire in our cohort.

\section{Self-reported HRQOL}

The mean self-rated health grade (EuroQoL) was 6.46 \pm 1.40 for women, while men reported mean grades of $6.84 \pm 1.49$ ( $\mathrm{t}$ value $4.32, \mathrm{p}<0.001$ ). Women also reported a significantly lower HRQOL in 8 of the $10 \mathrm{HRQOL}$ measures as compared with men. Only the score for the RAND-36 domain health change was higher in women than in men. The RAND-36 domain general health did not differ between men and women. HRQOL measures per gender are shown in table 1.

When we stratified by indication for CAG (see online supplementary table), the EuroQoL self-rated health grade was significantly lower for women presenting with stable CAD $(6.4 \pm 1.4$ vs $6.7 \pm 1.5, \mathrm{p}<0.001)$ or myocardial infarction (6.6 \pm 1.4 vs $7.0 \pm 1.4, \mathrm{p}=0.039)$, but not among women who presented with unstable angina or 'other' indications.

Table 2 Self-reported anginal symptoms characteristics, stratified by gender

\begin{tabular}{|c|c|c|c|c|c|c|}
\hline & Men & $\mathbf{n}$ & Women & $\mathbf{n}$ & $\chi^{2}$ & p Value \\
\hline \multicolumn{7}{|l|}{ Type of symptoms } \\
\hline Chest pain (\%) & 57.5 & 587 & 59.4 & 238 & 0.35 & 0.54 \\
\hline Shortness of breath (\%) & 32.7 & 334 & 44.1 & 177 & 16.23 & $<0.001$ \\
\hline Other symptoms (\%) & 19.7 & 201 & 17.7 & 71 & 0.74 & 0.39 \\
\hline No symptoms (\%) & 17.5 & 178 & 9.7 & 39 & 13.28 & $<0.001$ \\
\hline Progressive symptoms (\%) & 52.0 & 427 & 60.7 & 134 & 7.34 & 0.007 \\
\hline \multicolumn{7}{|l|}{ Triggers of symptoms } \\
\hline Exercise (\%) & 57.9 & 591 & 58.6 & 235 & 0.05 & 0.82 \\
\hline Emotion (\%) & 12.7 & 130 & 19.5 & 78 & 10.36 & 0.001 \\
\hline Cold temperature (\%) & 14.5 & 148 & 12.7 & 51 & 0.77 & 0.38 \\
\hline No triggers (\%) & 25.0 & 255 & 30.4 & 122 & 4.34 & 0.04 \\
\hline \multicolumn{7}{|l|}{ Start of symptoms } \\
\hline More than 10 years (\%) & 21.2 & 173 & 14.9 & 51 & 3.24 & 0.07 \\
\hline $5-10$ years ago $(\%)$ & 11.6 & 95 & 15.8 & 54 & 5.65 & 0.02 \\
\hline $1-5$ years ago $(\%)$ & 31.1 & 254 & 38.6 & 132 & 9.62 & 0.002 \\
\hline Less than 1 year ago (\%) & 36.1 & 295 & 30.7 & 105 & 0.63 & 0.43 \\
\hline \multicolumn{7}{|l|}{ Last symptoms } \\
\hline More than 1 year ago (\%) & 17.8 & 143 & 13.8 & 46 & 1.28 & 0.26 \\
\hline 1 year to 1 month ago (\%) & 38.2 & 306 & 34.22 & 114 & 0.13 & 0.72 \\
\hline 1 month to 1 week ago (\%) & 19.1 & 153 & 19.8 & 66 & 0.64 & 0.42 \\
\hline Last week (\%) & 24.9 & 200 & 32.1 & 107 & 8.88 & 0.003 \\
\hline \multicolumn{7}{|l|}{ Limitations by symptoms } \\
\hline None (\%) & 20.5 & 168 & 13.1 & 45 & 5.36 & 0.02 \\
\hline Mild limitations (\%) & 42.5 & 348 & 47.5 & 163 & 5.63 & 0.02 \\
\hline Severe limitations (\%) & 30.5 & 250 & 30.9 & 106 & 0.80 & 0.37 \\
\hline No activity possible (\%) & 6.5 & 53 & 8.5 & 29 & 2.41 & 0.12 \\
\hline
\end{tabular}

Self-reported anginal symptoms characteristics, stratified by gender. The percentage and $\mathrm{n}$ display the proportion and number of positive responses. The $\mathrm{p}$ value is derived from Pearson $\chi^{2}$ testing. 
Women who presented with stable CAD symptoms showed lower scores on 8/9 RAND-36 domains, with unstable angina on the 1/9 RAND-36 domain, with myocardial infarction on 6/9 RAND-36 domains and women presenting with 'other' indications showed lower scores on the 1 RAND-36 domain.

Stratified by angiographic CAD severity, the EuroQoL self-rated health grade was lower in women with no CAD $(6.3 \pm 1.4$ vs $6.8 \pm 1.5, \mathrm{p}=0.003)$ and women with singlevessel disease $(6.6 \pm 1.4$ vs $6.9 \pm 1.5, \mathrm{p}=0.039)$, but did not differ significantly among patients with double-vessel or triple-vessel disease. Significantly lower scores were found for women in 6/9 RAND-36 domains among patients with no angiographic CAD, in 8/9 RAND-36 domains among patients with single-vessel CAD, in 7/9 RAND-36 domains among patients with double-vessel CAD and in 4/9 RAND-36 domains for patients with triple-vessel disease.

When we looked into the treatment of CAD, women treated conservatively and with PCI reported lower EuroQoL self-rated health grades $(6.4 \pm 1.4$ vs $6.7 \pm 1.5$, $\mathrm{p}=0.008$ and $6.5 \pm 1.4$ vs $6.9 \pm 1.5, \mathrm{p}=0.003$, respectively) than men. No significant gender difference for the EuroQoL self-rated health grade was found for patients treated with CABG. Women reported lower scores on 7/9 RAND-36 domains when treated conservatively, on $8 / 9$ RAND-36 domains when treated with PCI and on 5/9 RAND-36 domains when treated with CABG.

HRQOL scores of male patients with myocardial infarction were significantly higher than those of male patients presenting with stable CAD, for 2/9 RAND-36 domains (physical functioning and general health), which was not seen in the case of women. Also, among male patients presenting with an 'other' indication, these domains were higher as compared with stable male patients with CAD. In addition, general health was higher in women presenting with an 'other' indication as compared with women presenting with stable CAD.

Remarkably, men and women did not show a significant difference in HRQOL (EuroQoL) across the severities of CAD.

General health was higher in men treated with PCI and CABG as compared with men who were treated conservatively. For women, a difference was found in health change when they were treated with CABG as compared with conservative treatment.

\section{Comparison with general population}

Participants (men and women combined) in our cohort reported lower RAND-36 HRQOL scores than their agematched counterparts who were randomly sampled from the Dutch population, as described by van der Zee and Sanderman. ${ }^{21}$ For the age category 55-64 years, the average difference across the RAND-36 HRQOL domains was 8.5 points lower in our cohort than in the general population. For the age category 65-75, the average difference was 5.9 points lower than in the general population (data not shown).
As shown in table 3, we calculated the difference in HRQOL scores between our cohort and the general Dutch population stratified by gender (all significantly lower in our cohort), and observed that $\Delta$ was larger in women than in men. Women's HRQOL scores were 2-13.4 points lower than men's scores across the nine domains of the RAND-36, indicating a larger suppressing effect of CAD on HRQOL in women than in men. Women appeared to be more severely affected and restricted by chest pain and CAD than men, as reflected by greater differences in their HRQOL scores.

\section{Gender differences in associations of patient characteristics with HRQOL}

The associations of patient characteristics with the EuroQoL self-graded health grade are displayed in table 4, stratified by gender. These associations were tested in a univariable manner and in a multivariable manner. Interactions of patient characteristics with gender were evaluated in both analyses. $\beta s$ in table 4 represent the change in the EuroQoL self-rated health grade for a given change in the patient characteristic.

In the univariable models, significant gender interactions were found for diabetes, a history of CVD and shortness of breath. Diabetes was associated with lower HRQOL in men $(\beta=-0.46, p<0.001)$ but not in women $(\beta=0.02, p=0.9, p$ value for interaction 0.028$)$. Having a history of CVD was also associated with lower HRQOL in men but not in women $(\beta=-0.60, p<0.001$ for men, $\beta=-0.17, p=0.24$ for women, $p$ value for interaction $0.013)$. Shortness of breath was associated with lower HRQOL in men and women, but the effect size was significantly greater in men $(\beta=-0.87, p<0.001$ vs $\beta=-0.44$, $\mathrm{p}=0.002$ for women, $\mathrm{p}$ value for interaction 0.013 ).

In the multivariable model, no significant gender interactions were found.

\section{DISCUSSION}

In this study, we demonstrated that self-reported HRQOL differed by gender in patients undergoing CAG regardless of the indication for CAG, CAD severity and treatment of CAD (conservative, PCI or CABG). Women showed a larger difference in HRQOL as compared with the general population than men. Furthermore, gender differences were found in the associations of patient characteristics with HRQOL.

\section{HRQOL scores}

In our cohort, we found that women consistently reported lower HRQOL scores than men for both the EuroQoL self-rated health grade and the RAND-36 domains. This has previously been described by Norris et $a l^{15}$ in a cohort of patients with established CAD and also in patients with severe CAD undergoing CABG. ${ }^{17}{ }^{24}$ In addition to existing literature, we showed that gender differences in HRQOL are observable throughout all indications and severities of CAD. Remarkably, the 


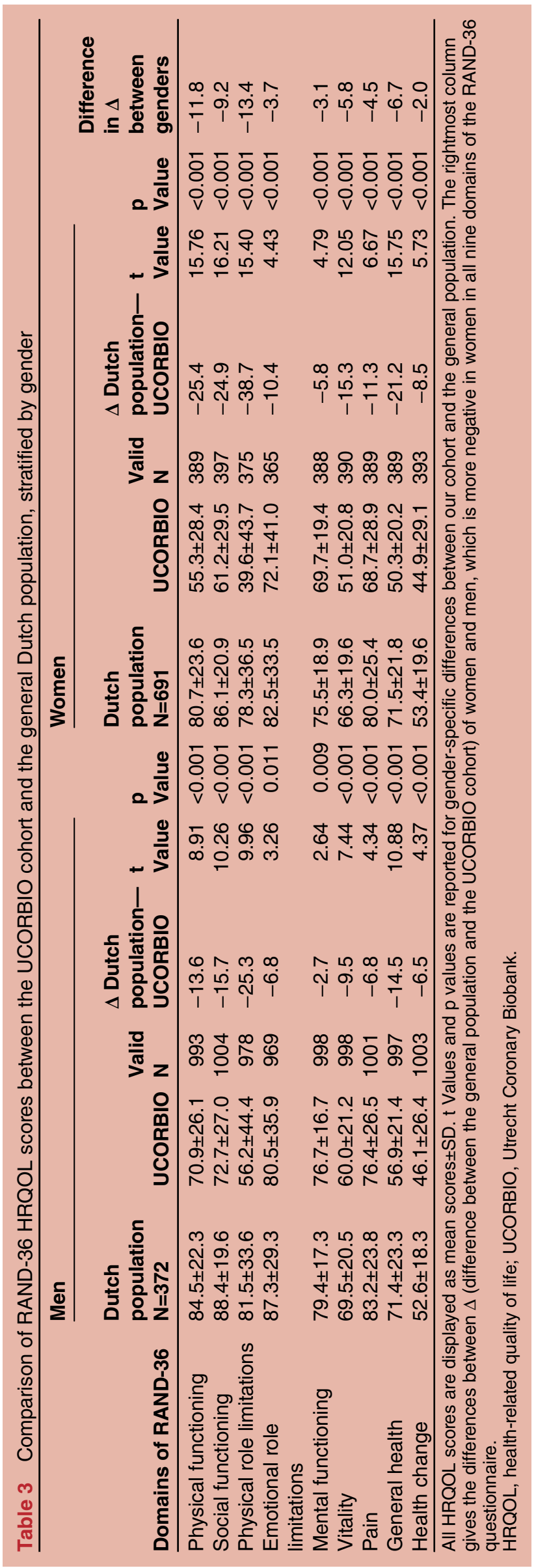

gender differences were also found in patients in whom no significant epicardial CAD could be objectified by CAG and in whom no invasive treatment was undertaken.

Gender differences in HRQOL can already be observed in the general Dutch population, where women report slightly lower HRQOL scores, although not consistently across all domains of the RAND-36 questionnaire (average difference across the 9 domains 2.6 points). ${ }^{21}$ In our cohort, the difference between men and women is on average 9.3 points, indicating that the baseline difference between men and women is amplified in a population in which CAG is indicated and that HRQOL apparently is more strongly affected in women than in men. To the best of our knowledge, this phenomenon has not been reported before.

\section{Patient characteristics associated with HROOL}

In our study, we found significant interactions of gender with diabetes, history of CVD and shortness of breath. In all three cases, the association of the patient characteristic with lower HRQOL was stronger in men than in women. HRQOL in women is not possibly so much determined by CVD risk factors, a history of CVD or other general patient characteristics but more by other factors such as hormonal status (menopause) and psychosocial factors that were not measured in this study. Menopause has previously been shown to have a negative impact on some domains of HRQOL scores. ${ }^{25}$ However, in our cohort, we do not observe more extreme gender differences in HRQOL in the age group of 55-64 in which postmenopausal symptoms would occur (data not shown). Also, it has been shown that depression is related to HRQOL, ${ }^{17}$ although depression and social support could also not completely explain the gender difference in HRQOL in a study by Norris $e t a l^{15}$ Unknown factors or factors that were not included in this study might better explain HRQOL in women. Socioeconomic status, ${ }^{26}$ lifestyle and noncardiovascular comorbidities might account for a part of the unexplained variance, but were unfortunately not available in this study. Efforts should be pursued to elucidate the factors that determine the low HRQOL in women. When we know which factors determine low HRQOL in women, more targeted approaches can be sought in order to improve HRQOL in women.

\section{Microvascular disease}

Surprisingly, patients in whom eventually no significant CAD could be objectified reported HRQOL scores that were equal to those in patients who were diagnosed with triple-vessel disease (eg, mean EuroQoL self-rated health grade 6.3 in both no $\mathrm{CAD}$ and triple-vessel disease for women and 6.8 and 6.7 for men, respectively). HRQOL is possibly compromised in these patients with "healthy coronaries" in the same way as with significant CAD due to symptoms of microvascular disease or spasms of the coronary arteries or microvascular system, which cannot be 


\begin{tabular}{|c|c|c|c|c|c|c|c|c|c|c|c|c|c|c|}
\hline & Univariable & & & & & & & Multivariable & & & & & & \\
\hline & Men & & & Women & & & & Men & & & Women & & & \\
\hline & B (95\% Cl) & $\begin{array}{l}\mathbf{t} \\
\text { Value } \\
\end{array}$ & $\begin{array}{l}\mathbf{p} \\
\text { Value } \\
\end{array}$ & B (95\% Cl) & $\begin{array}{l}t \\
\text { Value } \\
\end{array}$ & $\begin{array}{l}\mathbf{p} \\
\text { Value } \\
\end{array}$ & $\begin{array}{l}\mathrm{p} \\
\text { Interaction }\end{array}$ & B (95\% Cl) & $\begin{array}{l}\mathbf{t} \\
\text { Value } \\
\end{array}$ & $\begin{array}{l}p \\
\text { Value } \\
\end{array}$ & B (95\% Cl) & $\begin{array}{l}\mathbf{t} \\
\text { Value } \\
\end{array}$ & $\begin{array}{l}p \\
\text { Value } \\
\end{array}$ & $\begin{array}{l}\mathbf{p} \\
\text { Interaction } \\
\end{array}$ \\
\hline Age (per 10 years) & $-0.06(-0.15$ to 0.03$)$ & -1.31 & 0.191 & $-0.04(-0.17$ to 0.08$)$ & -0.71 & 0.479 & 0.856 & 0.13 (0.03 to 0.23$)$ & 2.53 & 0.012 & $0.04(-0.11$ to 0.19$)$ & 0.50 & 0.615 & 0.510 \\
\hline BMI (per 5 points) & $-0.14(-0.25$ to -0.03$)$ & -2.57 & 0.010 & $-0.06(-0.20$ to 0.08$)$ & -0.79 & 0.429 & 0.348 & $0.06(-0.06$ to 0.18$)$ & 0.92 & 0.359 & $-0.05(-0.22$ to 0.12$)$ & -0.62 & 0.537 & 0.933 \\
\hline Diabetes & $-0.46(-0.69$ to -0.24$)$ & -4.03 & $<0.001$ & $0.02(-0.34$ to 0.37$)$ & 0.09 & 0.928 & $0.028^{*}$ & $-0.11(-0.39$ to 0.16$)$ & -0.82 & 0.415 & $0.06(-0.35$ to 0.47$)$ & 0.30 & 0.762 & 0.342 \\
\hline Hypertension & $-0.42(-0.61$ to -0.23$)$ & -4.40 & $<0.001$ & $-0.21(-0.50$ to 0.08$)$ & -1.41 & 0.160 & 0.248 & $-0.34(-0.57$ to -0.11$)$ & -2.95 & 0.003 & $0.02(-0.34$ to 0.38$)$ & 0.10 & 0.918 & 0.071 \\
\hline Hypercholesterolaemia & $-0.32(-0.51$ to -0.14$)$ & -3.38 & 0.001 & $-0.12(-0.41$ to 0.17$)$ & -0.81 & 0.420 & 0.252 & $-0.06(-0.29$ to 0.17$)$ & -0.50 & 0.614 & $-0.03(-0.36$ to 0.30$)$ & -0.17 & 0.868 & 0.523 \\
\hline Smoking & $-0.26(-0.46$ to -0.06$)$ & -2.55 & 0.011 & $-0.10(-0.41$ to 0.21$)$ & -0.64 & 0.524 & 0.409 & $-0.17(-0.38$ to 0.04$)$ & -1.55 & 0.122 & $-0.22(-0.56$ to 0.11$)$ & -1.30 & 0.194 & 0.982 \\
\hline History of CVD & $-0.60(-0.78$ to -0.42$)$ & -6.45 & $<0.001$ & $-0.17(-0.45$ to 0.11$)$ & -1.18 & 0.240 & $0.013^{*}$ & $-0.33(-0.57$ to -0.09$)$ & -2.71 & 0.007 & $-0.08(-0.41$ to 0.26$)$ & -0.45 & 0.651 & 0.236 \\
\hline $\begin{array}{l}\text { Stable CAD (vs UA or } \\
\text { infarction) }\end{array}$ & $-0.25(-0.44$ to -0.05$)$ & -2.48 & 0.013 & $-0.32(-0.62$ to -0.02$)$ & -2.12 & 0.035 & 0.684 & $0.05(-0.19$ to 0.29$)$ & 0.40 & 0.688 & $-0.21(-0.59$ to 0.17$)$ & -1.08 & 0.283 & 0.464 \\
\hline Significant CAD & $0.05(-0.18$ to 0.28$)$ & 0.40 & 0.688 & $0.19(-0.10$ to 0.48$)$ & 1.28 & 0.200 & 0.460 & $0.25(-0.14$ to 0.65$)$ & 1.25 & 0.212 & $0.07(-0.53$ to 0.67$)$ & 0.23 & 0.819 & 0.988 \\
\hline $\begin{array}{l}\text { Conservative treatment } \\
\text { (vs } \mathrm{PCl} \text { or } \mathrm{CABG} \text { ) }\end{array}$ & $-0.15(-0.36$ to 0.05$)$ & -1.52 & 0.129 & $-0.15(-0.44$ to 0.13$)$ & -1.07 & 0.283 & 0.995 & $0.00(-0.35$ to 0.34$)$ & -0.02 & 0.983 & $-0.14(-0.73$ to 0.44$)$ & -0.49 & 0.628 & 0.885 \\
\hline Chest pain & $-0.36(-0.54$ to -0.17$)$ & -3.76 & $<0.001$ & $-0.29(-0.58$ to -0.01$)$ & -2.02 & 0.044 & 0.711 & $-0.19(-0.41$ to 0.04$)$ & -1.61 & 0.108 & $-0.32(-0.66$ to 0.03$)$ & -1.78 & 0.076 & 0.944 \\
\hline Shortness of breath & $-0.87(-1.06$ to -0.68$)$ & -9.00 & $<0.001$ & $-0.44(-0.72$ to -0.16$)$ & -3.11 & 0.002 & $0.013^{*}$ & $-0.48(-0.71$ to -0.26$)$ & -4.24 & $<0.001$ & $-0.14(-0.48$ to 0.20$)$ & -0.84 & 0.403 & 0.099 \\
\hline Progressive symptoms & $-0.65(-0.85$ to -0.45$)$ & -6.35 & $<0.001$ & $-0.69(-0.98$ to -0.40$)$ & -4.75 & $<0.001$ & 0.838 & $-0.23(-0.45$ to -0.02$)$ & -2.11 & 0.035 & $-0.51(-0.88$ to -0.14$)$ & -2.70 & 0.008 & 0.486 \\
\hline $\begin{array}{l}\text { Symptoms with } \\
\text { exercise }\end{array}$ & $-0.35(-0.54$ to -0.17$)$ & -3.72 & $<0.001$ & $-0.18(-0.46$ to 0.11$)$ & -1.21 & 0.227 & 0.315 & $0.05(-0.19$ to 0.29$)$ & 0.43 & 0.666 & $0.06(-0.30$ to 0.42$)$ & 0.32 & 0.749 & 0.831 \\
\hline $\begin{array}{l}\text { Symptoms with } \\
\text { emotion }\end{array}$ & $-0.48(-0.76$ to -0.21$)$ & -3.45 & 0.001 & $-0.38(-0.73$ to -0.03$)$ & -2.13 & 0.033 & 0.655 & $-0.21(-0.51$ to 0.09$)$ & -1.40 & 0.162 & $-0.24(-0.61$ to 0.13$)$ & -1.27 & 0.206 & 0.898 \\
\hline Symptoms with cold & $-0.47(-0.73$ to -0.21$)$ & -3.55 & $<0.001$ & $-0.11(-0.53$ to 0.31$)$ & -0.51 & 0.614 & 0.160 & $-0.25(-0.52$ to 0.03$)$ & -1.75 & 0.081 & $0.18(-0.26$ to 0.63$)$ & 0.81 & 0.417 & 0.115 \\
\hline $\begin{array}{l}\text { Start of symptoms } \\
\text { (short vs long) }\end{array}$ & 0.56 (0.34 to 0.77$)$ & 5.03 & $<0.001$ & 0.36 (0.05 to 0.67$)$ & 2.28 & 0.023 & 0.325 & $0.20(-0.05$ to 0.44$)$ & 1.59 & 0.113 & $0.22(-0.14$ to 0.57$)$ & 1.22 & 0.225 & 0.889 \\
\hline $\begin{array}{l}\text { Last symptoms (recent } \\
\text { vs long) }\end{array}$ & $-0.77(-0.98$ to -0.57$)$ & -7.41 & $<0.001$ & $-0.74(-1.02$ to -0.45$)$ & -5.09 & $<0.001$ & 0.849 & $-0.58(-0.79$ to -0.36$)$ & -5.31 & $<0.001$ & $-0.67(-0.99$ to -0.34$)$ & -4.04 & $<0.001$ & 0.809 \\
\hline $\begin{array}{l}\text { Limitations due to } \\
\text { symptoms }\end{array}$ & $-0.93(-1.13$ to -0.72$)$ & -8.93 & $<0.001$ & $-0.71(-1.00$ to -0.43$)$ & -4.89 & $<0.001$ & 0.250 & $-0.53(-0.76$ to -0.31$)$ & -4.60 & $<0.001$ & $-0.42(-0.77$ to -0.07$)$ & -2.37 & 0.018 & 0.671 \\
\hline \multicolumn{15}{|c|}{$\begin{array}{l}\text { Regression coefficients ( } \beta \text { s) for the EuroQoL self-rated health grade (scale 1-10) stratified by gender, obtained from a univariable regression model (left part of table) and from a multivariable } \\
\text { linear regression model containing: diabetes, hypertension, smoking, hypercholesterolaemia, history of CVD, age, BMI, indication for CAG (stable CAD, UA, myocardial infarction), treatment of } \\
\text { CAD (conservative, PCI, CABG), angiographic significance of CAD, time since first symptoms, time since last symptoms, limitations due to symptoms, chest pain, shortness of breath, triggers of } \\
\text { symptoms (exercise, emotion, cold) and progression of symptoms. } \beta \text { is described for yes versus no, unless indicated otherwise. The significance of the interaction terms is given in the columns } \\
\text { "p interaction". } \\
\text { *Indicates p value for interaction <0.05. Significantly different univariable } \beta \text { s were found for diabetes, history of CVD and shortness of breath. No multivariable interaction terms were found to be } \\
\text { significant. } \\
\text { BMl, body mass index; CABG, coronary artery bypass grafting; CAD, coronary artery disease; CAG, coronary angiography; CVD, cardiovascular disease; PCI, percutaneous coronary } \\
\text { intervention: UA, unstable angina. }\end{array}$} \\
\hline
\end{tabular}


visualised on CAG. These conditions might give rise to symptoms similar to macrovascular epicardial disease. As opposed to macrovascular disease, which is more common among men, microvascular disease has been reported to be equally common between the genders. ${ }^{27}$ Since microvascular disease is more complicated to diagnose, it is often unrecognised and thus undertreated. ${ }^{28} 2930$ Most importantly, the presence of microvascular disease is associated with poor outcome and thus should not be trivialised. ${ }^{27} 31$ The predictors of microvascular disease in women may lie, at least in part, in female-specific risk factors, for example, oestrogen deficiency. ${ }^{32}$ These factors, unfortunately, were not available for our analysis.

\section{Limitations}

A limitation of our study is that we could control the moment a patient decides to fill in and return their questionnaire. A considerable spread in delay was observed, ranging from 0 to 743 days with a median delay of 112 days (IQR 22-338 days) between the date of CAG and the date of returning the questionnaire. There was a significant but very limited effect of delay of questionnaire return (per 100 days) with the EuroQoL selfrated health grade $(\beta 0.06, p=0.007)$, indicating that with every 100-day increase in delay the EuroQoL self-rated health grade was 0.06 points higher.

In the analyses discussed in this paper, we were unable to take a possible response bias into account. At baseline, the responders and non-responders did not differ markedly (data not shown). In summary: they were younger, less often had a history of CVD and more often presented with myocardial infarction, assuming all other baseline characteristics were equal.

The indication group 'other' might be different from the regular indications for CAG. Therefore, we performed a sensitivity analysis without these patients, which yielded similar results.

Race-specific/ethnicity-specific analyses could not be performed due to the predominantly Caucasian (93\%) population that was studied.

\section{Implications}

Improving HRQOL is important because low HRQOL has been reported to lead to higher healthcare costs (hospital admission, emergency room and prescription expenditures). ${ }^{1}$ People with the lowest HRQOL scores utilise almost thrice the annual healthcare costs of people with the highest HRQOL scores ( $>$ US $\$ 5000$ vs $<$ US $\$ 2000$ ).

Diabetes, a positive history of CVD and symptoms of shortness of breath were more strongly associated with HRQOL in men. Diabetes is treated with antidiabetic drugs, a strict regime of glucose checks and lifestyle adaptations, which can be a great burden for patients. Awareness of the benefit of strict glucose control might alleviate depressed HRQOL among patients with diabetes. $^{33}$

General strategies in order to prevent CVD in men could be beneficial in terms of HRQOL (albeit in the long term), as a history of CVD is associated with lower HRQOL in men.

The characteristics of symptoms were associated with HRQOL in men and women. Specific symptom-focused treatment might be beneficial to improve HRQOL, especially in women, in whom no other factors associating with HRQOL could be determined.

In the current guidelines on the treatment of stable angina, in patients with typical symptoms but no epicardial CAD, it is advised to undertake further diagnostic tests to assess microvascular ischaemic heart disease. ${ }^{34}$ However, even when patients with microvascular disease are treated according to the guidelines, recurrent symptoms are common..$^{35}$ Additional pain relief interventions or coping programmes should be considered in patients with refractory or microvascular anginal symptoms in order to improve HRQOL. ${ }^{36}$

The difference in HRQOL was significant between men and women in our study; however, the clinical and personal relevance of this difference remains unclear. Future studies need to evaluate whether repressed HRQOL in men and women has similar consequences for, for example, hospitalisations, medication utilisation and the ability to participate in work and social activities.

\section{CONCLUSION}

Women reported lower HRQOL than men throughout all indications for CAG and regardless of CAD severity and treatment. As compared with the general population, the reduction in HRQOL was more extreme in women than in men. Furthermore, there were evident gender differences in determinants of diminished HRQOL scores in patients undergoing CAG. These differences deserve attention in future research.

\section{Author affiliations}

${ }^{1}$ Laboratory of Experimental Cardiology, Division Heart and Lungs, University Medical Centre Utrecht, Utrecht, The Netherlands

${ }^{2}$ ICIN-Netherlands Heart Institute, Utrecht, The Netherlands

${ }^{3}$ Department of Cardiology, Division Heart and Lungs, University Medical Centre Utrecht, Utrecht, The Netherlands

${ }^{4}$ Durrer Center for Cardiogenetic Research, ICIN-Netherlands Heart Institute, Utrecht, The Netherlands

${ }^{5}$ Faculty of Population Health Sciences, Institute of Cardiovascular Science, University College London, London, UK

${ }^{6}$ Department of Cardiology, VU University Medical Center, Amsterdam, The Netherlands

${ }^{7}$ Department of Surgery, Yong Loo Lin School of Medicine, National University of Singapore, Singapore, Singapore

${ }^{8}$ Cardiovascular Research Institute, National University Heart Centre, National University Health System, Singapore, Singapore

Acknowledgements The authors would like to thank Ms Jonne Hos for her excellent support of the UCORBIO cohort.

Contributors CMG analysed the data and drafted the manuscript. The other authors provided critical input for the manuscript, reviewed the analyses and edited the manuscript to its final version.

Funding This work was financially supported by the Royal Netherlands Academy of Art and Sciences via a strategic grant to the Interuniversity Cardiology Institute of the Netherlands (ICIN) and Dominique de Kleijn. 
Competing interests None declared.

Ethics approval METC Utrecht.

Provenance and peer review Not commissioned; externally peer reviewed.

Open Access This is an Open Access article distributed in accordance with the Creative Commons Attribution Non Commercial (CC BY-NC 4.0) license, which permits others to distribute, remix, adapt, build upon this work noncommercially, and license their derivative works on different terms, provided the original work is properly cited and the use is non-commercial. See: http:// creativecommons.org/licenses/by-nc/4.0/

\section{REFERENCES}

1. Harrison PL, Pope JE, Coberley CR, et al. Evaluation of the relationship between individual well-being and future health care utilization and cost. Popul Health Manag 2012;15:325-30.

2. Marquis $\mathrm{P}$, Caron M, Emery MP, et al. The role of health-related quality of life data in the drug approval processes in the US and Europe: a review of guidance documents and authorizations of medicinal products from 2006 to 2010. Pharmaceut Med 2011;25:147-60.

3. Hlatky MA, Chung SC, Escobedo J, et al. The effect of obesity on quality of life in patients with diabetes and coronary artery disease. Am Heart J 2010;159:292-300.

4. Oreopoulos A, Padwal R, McAlister FA, et al. Association between obesity and health-related quality of life in patients with coronary artery disease. Int J Obes (Lond) 2010;34:1434-41.

5. Uchmanowicz I, Loboz-Grudzien K, Jankowska-Polanska B, et al. Influence of diabetes on health-related quality of life results in patients with acute coronary syndrome treated with coronary angioplasty. Acta Diabetol 2013;50:217-25.

6. Stafford L, Berk M, Jackson HJ. Tobacco smoking predicts depression and poorer quality of life in heart disease. BMC Cardiovasc Disord 2013;13:35

7. Müller-Nordhorn J, Muckelbauer R, Englert $\mathrm{H}$, et al. Longitudinal association between body mass index and health-related quality of life. PLOS ONE 2014;9:e93071.

8. Al Hayek AA, Robert AA, Al Saeed A, et al. Factors associated with health-related quality of life among Saudi patients with type 2 diabetes mellitus: a cross-sectional survey. Diabetes Metab $J$ 2014;38:220-9.

9. Coste J, Quinquis L, D'Almeida S, et al. Smoking and health-related quality of life in the general population. Independent relationships and large differences according to patterns and quantity of smoking and to gender. PLOS ONE 2014;9:e91562.

10. Mendis S, Puska P, Norrving B. Global Atlas on cardiovascular disease prevention and control Geneva: WHO, 2011.

11. Jacobs AK. Coronary intervention in 2009: are women no different than men? Circ Cardiovasc Interv 2009;2:69-78.

12. Hemingway $\mathrm{H}$, Langenberg $\mathrm{C}$, Damant $\mathrm{J}$, et al. Prevalence of angina in women versus men: a systematic review and meta-analysis of international variations across 31 countries. Circulation 2008;117:1526-36.

13. Bruins Slot MH, Rutten FH, van der Heijden GJ, et al. Gender differences in pre-hospital time delay and symptom presentation in patients suspected of acute coronary syndrome in primary care. Fam Pract 2012;29:332-7.

14. Kaul P, Armstrong PW, Sookram S, et al. Temporal trends in patient and treatment delay among men and women presenting with ST-elevation myocardial infarction. Am Heart J 2011;161:91-7.

15. Norris CM, Spertus JA, Jensen L, et al. Sex and gender discrepancies in health-related quality of life outcomes among patients with established coronary artery disease. Circ Cardiovasc Qual Outcomes 2008;1:123-30.
16. Bakhai A, Ferrières $\mathrm{J}$, James $\mathrm{S}$, et al. Treatment, outcomes, costs, and quality of life of women and men with acute coronary syndromes who have undergone percutaneous coronary intervention: results from the antiplatelet therapy observational registry. Postgrad Med 2013;125:100-7.

17. Kendel F, Dunkel A, Müller-Tasch T, et al. Gender differences in health-related quality of life after coronary bypass surgery: results from a 1-year follow-up in propensity-matched men and women. Psychosom Med 2011;73:280-5.

18. VanderZee KI, Sanderman R, Heyink JW, et al. Psychometric qualities of the RAND 36-Item Health Survey 1.0: a multidimensional measure of general health status. Int J Behav Med 1996;3: 104-22

19. EuroQol Group. EuroQol-a new facility for the measurement of health-related quality of life. Health Policy 1990;16:220-33.

20. Rose GA, Blackburn H. Cardiovascular survey methods. Geneva, Switzerland: World Health Organization (Sales agent for UK., H. M. Stationery Office), 1968.

21. Van der Zee KI, Sanderman R. Het meten van de algemene gezondheidstoestand met de RAND-36: een handleiding. Rijksuniversiteit, Groningen, 1993:28. ISBN: 90-72156-60-9

22. Groningen RU. SYNTAX file RAND-36 V1. https://www.umcg.nl/ SiteCollectionDocuments/research/institutes/SHARE/assessment tools/syntax_file_rand-36_v1_withoutaggregatescores.pdf

23. R Core Team. R: A language and environment for statistical computing. R Foundation for Statistical Computing. Vienna, Austria: 2013. ISBN 3-900051-07-0, URL http://www.R-project.org/.

24. Martin LM, Holmes SD, Henry LL, et al. Health-related quality of life after coronary artery bypass grafting surgery and the role of gender. Cardiovasc Revasc Med 2012;13:321-7.

25. Hess R, Thurston RC, Hays RD, et al. The impact of menopause on health-related quality of life: results from the STRIDE Iongitudinal study. Qual Life Res 2012;21:535-44.

26. Degroote S, Vogelaers DP, Vermeir $\mathrm{P}$, et al. Socio-economic behavioural, (neuro)psychological and clinical determinants of HRQoL in people living with HIV in Belgium: a pilot study. J Int AIDS Soc 2013;16:18643.

27. Murthy VL, Naya M, Taqueti VR, et al. Effects of sex on coronary microvascular dysfunction and cardiac outcomes. Circulation 2014;129:2518-27.

28. Pries AR, Habazettl H, Ambrosio G, et al. A review of methods for assessment of coronary microvascular disease in both clinical and experimental settings. Cardiovasc Res 2008;80:165-74.

29. Shaw LJ, Bugiardini R, Merz CNB. Women and ischemic heart disease: evolving knowledge. J Am Coll Cardiol 2009;54:1561-75.

30. Bugiardini R, Bairey Merz CN. Angina with 'normal' coronary arteries: a changing philosophy. JAMA 2005;293:477-84

31. Gulati M, Cooper-DeHoff RM, McClure C, et al. Adverse cardiovascular outcomes in women with nonobstructive coronary artery disease: a report from the Women's Ischemia Syndrome Evaluation Study and the St James Women Take Heart Project. Arch Intern Med 2009;169:843-50.

32. Banks K, Lo M, Khera A. Angina in women without obstructive coronary artery disease. Curr Cardiol Rev 2010;6:71-81.

33. Cox DJ. Blood glucose awareness training: what is it, where is it, and where is it going? Diabetes Spectr 2006;19:43-9.

34. Montalescot G, Sechtem U, Achenbach S, et al. 2013 ESC guidelines on the management of stable coronary artery disease: the Task Force on the management of stable coronary artery disease of the European Society of Cardiology. Eur Heart J 2013;34:2949-3003.

35. Shaw LJ, Bairey Merz CN, Pepine CJ, et al. Insights from the NHLBI-Sponsored Women's Ischemia Syndrome Evaluation (WISE) study: part I: gender differences in traditional and novel risk factors, symptom evaluation, and gender-optimized diagnostic strategies. J Am Coll Cardiol 2006;47:S4-20.

36. Lanza GA, Parrinello R, Figliozzi S. Management of microvascular angina pectoris. Am J Cardiovasc Drugs 2014;14:31-40. 